\title{
Impact and Management of MRSA in the Long-Term Care Setting
}

\author{
Christopher J. Crnich
}

Published online: 5 June 2013

(C) Springer Science+Business Media New York 2013

\begin{abstract}
Methicillin-resistant Staphylococcus aureus (MRSA) is a major cause of morbidity and mortality in healthcare facilities. Residents of nursing homes are commonly colonized with MRSA and acquisition within these facilities is common. While treatment of MRSA infection in the NH is more costly than treatment of infections caused by methicillin-susceptible strains, the frequency of serious infections and attributable mortality remains uncommon. Consequently, controlling the spread of MRSA in NHs is primarily a population health concern and interventions to control intrafacility transmissions should be balanced with a concern for resident quality-of-life.
\end{abstract}

Keywords Methicillin-resistant Staphylococcus aureus . Nursing homes $\cdot$ Elderly

\section{Introduction}

Infections caused by methicillin-resistant Staphylococcus aureus (MRSA) are a major cause of morbidity and mortality in the United States $[1 \bullet, 2 \cdot 3 \bullet]$. The number of MRSA infections among hospitalized patients increased from 127,000 to 280,000 cases from the years 1999 to 2005 [1 $]$. Over a similar timeframe, healthcare costs generated by MRSArelated hospitalizations increased $\sim 70 \%$ from $\$ 8.7$ billion in 1998 to $\$ 14.5$ billion in 2003 [4]. For incompletely understood reasons, rates of invasive MRSA infections have declined since their peak in 2005 [5]. These encouraging trends notwithstanding, nearly $5 \%$ of patients hospitalized with an

C. J. Crnich $(\bowtie)$

School of Medicine and Public Health, University of Wisconsin, 1685 Highland Avenue, MFCB 5217,

Madison, WI 53705, USA

e-mail: cjc@medicine.wisc.edu

C. J. Crnich

William S. Middleton Veterans Affairs Hospital, Madison, WI, USA
MRSA infection die [3•] and MRSA remains one of the leading causes of death in the United States $[2 \bullet]$.

Hospitalizations for infection and septicemia disproportionately occur among the elderly $[6,7]$. MRSA illness patterns in the elderly largely mirror these population trends. Despite representing only $13 \%$ of the population, $45 \%$ of hospitalizations and $70 \%$ of the deaths associated with an MRSA infection occur in patients over the age of $65[2 \cdot, 3 \bullet$, 5]. Nursing home residents are a particularly vulnerable elderly subgroup that is at an elevated risk of developing invasive MRSA infections when hospitalized [8]. Nevertheless, it is not clear that asymptomatic MRSA colonization adversely affects resident health outcomes outside acute care settings [9] despite its widespread prevalence in nursing homes [10-13]. The purpose of this review is to examine the epidemiology of MRSA in nursing homes, the impact colonization has on resident outcomes, strategies for managing residents with symptomatic infection, and a pragmatic approach to residents with asymptomatic colonization.

\section{Epidemiologic Patterns of MRSA Colonization in Nursing Homes}

MRSA in nursing homes was first reported in 1970, but it was not until the early 1990s that serious attempts to characterize the prevalence of MRSA in nursing homes were reported [14, $15 \bullet, 16 \cdot$. The reported prevalence of MRSA in these studies, all of which were performed in Veterans Administration extended care facilities, ranged from 16-34\%. Early studies of MRSA in community nursing homes found considerably lower rates of prevalent colonization $(\sim 10 \%)[17,18]$. However, more recent studies suggest that approximately $25 \%$ of nursing home residents are colonized with MRSA, although there is considerable variation observed across facilities $[12,13]$. Colonization may be extranasal in approximately $65 \%$ of residents, [19•] and persistent or intermittent colonization has been documented in approximately $85 \%$ of the residents who 
are followed longitudinally $[16 \bullet, 20]$. Persistently colonized residents harbor higher MRSA colony counts on body surfaces than intermittently colonized residents [10], and these individuals have a substantially higher risk of developing infection as compared to residents with intermittent or transient carriage [15•].

It is commonly assumed that a majority of the MRSA observed in NHs is the result of importation from acute care facilities, except in outbreak situations [14, 21, 22]. Indeed, early studies examining the frequency of acquisition of MRSA in NHs failed to identify significant levels of transmission between MRSA-discordant roommates [16•, 17]. However, a number of recent studies have demonstrated that MRSA acquisition in NHs is substantial [23, 24•, 25, 26, 27•]. For example, $26 \%$ of residents in California nursing homes were found to be colonized with MRSA during a recently published point-prevalence study in 26 facilities, however, the MRSA prevalence among new admissions to these facilities was only $15 \%[1 \bullet, 2 \bullet, 26,28]$. Similarly, longitudinal studies have found that 8 to $20 \%$ of subjects free of colonization at baseline subsequently acquire MRSA during follow-up [ $1 \bullet$, $23,24 \cdot, 27 \bullet]$. Despite this level of acquisition, rates of transmission between roommates remain low $[4,24 \bullet, 27 \bullet]$ suggesting that other routes of transmission are responsible for the majority of MRSA acquisitions observed in NHs. A higher risk of MRSA acquisition observed among residents receiving rehabilitation services ( $\mathrm{HR}=4.0,95 \% \mathrm{CI} 2.2-8.8)$ and those who are bedbound (aHR 4.3-4.8) suggests that indirect spread through contact with healthcare workers may be significant mechanism of MRSA transmission in $\mathrm{NHs}$ [5, 24.]. Nevertheless, our understanding of the sources and modes of MRSA transmission in NHs remains incompletely understood at this time.

Unique strains of MRSA that emerged in community settings independently of healthcare-associated MRSA (HA-MRSA) have become a major problem in recent years $[3 \cdot, 29]$. Community-acquired MRSA (CA-MRSA; also referred to as the USA300 clone) possesses unique genetic characteristics that may confer higher virulence. These strains are now the most common cause of skin and soft tissue infections in many geographic regions and these strains have increasingly been implicated as a cause of invasive infection such as bacteremia, necrotizing fasciitis and necrotizing pneumonia [30, 31]. CA-MRSA strains are now a common cause of healthcareassociated infections in many regions $[6,7,32]$ and there is a concern that these strains will eventually become established in NHs $[2 \cdot, 5,28,33]$. While USA300 strains account for a minority of MRSA in most NHs [8, 19•, 34], CA-MRSA has become widespread among $\mathrm{NHs}$ in some geographic regions $[9,35]$ and has even become the dominant circulating strain in some long-term care facilities (LTCFs) [10, 12, 24•, 36, 37]. What this means for risk of infection in NHs is unclear. New introductions of HA-MRSA strains did lead to observable increases in the number of infections in some NHs in the 1980s and 1990s $[14,15 \cdot 16 \cdot, 21,22]$. Similarly, a large LTCF in California recently reported a significant increase in the incidence of skin and soft tissue infections that ran parallel with an increased prevalence of USA300 in the facility [17, 18, 36]. However, a recently published study performed in two LTCFs in Maryland found no difference in rates of subsequent infection among NH residents colonized with USA300 versus nonUSA300 MRSA strains [12, 13, 34].

\section{Impact of MRSA Colonization on Resident Outcomes and Risk of Infection}

MRSA carriage is a well-established risk factor for risk of subsequent infection [19•, 38]. A majority of studies examining this risk have been performed in the hospital setting and the impact of colonization on risk of infection among residents of NHs is less well established. Nevertheless, NH residents colonized with MRSA do appear to experience within-NH rates of infection that are twofold to sixfold higher than observed among residents who are $\operatorname{MRSA}(-)[15 \bullet, 16 \bullet, 20,39]$. The risk of infection among $\mathrm{NH}$ residents who are persistently colonized with MRSA [10, 40, 41] and those who are colonized when hospitalized may be substantially higher $[8,15 \bullet]$.

Despite an elevated risk of infection relative to noncolonized residents, the absolute impact of MRSA colonization on resident outcomes appears to be modest. Approximately $8 \%$ of MRSA $(+)$ residents who remain in a NH for a year will develop an infection caused by MRSA (Table 1). Skin and soft tissue infections are the most common type of infection caused by MRSA in this setting and serious invasive infections requiring hospitalization, such as pneumonia and bacteremia, remain uncommon manifestations of MRSA in the NH. A higher risk of death among residents colonized with MRSA has been reported in several observational studies [14, 21, 22, 42, 43]. Given the low rate of mortality attributable to MRSA in the studies summarized in Table 1 ( $<1$ per resident-year), the higher mortality observed in these studies may represent a spurious association influenced by higher levels of frailty among colonized residents $[16 \cdot, 17,18]$. Despite a limited impact on mortality, colonized residents who develop an MRSA infection in the $\mathrm{NH}$ may require hospitalization for administration of parenteral antibiotic therapy $[16 \bullet, 23,24 \bullet, 25,26,27 \bullet, 44]$ and treatment remains substantially more expensive than treatment of infection caused by methicillin-susceptible $S$. aureus even when managed within the $\mathrm{NH}[18,45]$.

As noted, CA-MRSA may possess enhanced transmissibility and virulence compared to HA-MRSA and there is concern that its introduction into NHs may translate into an increased risk of infection. The number of skin and soft tissue cultures identified as positive for MRSA quadrupled over a 10-year period in a single large California LTCF that experienced significant penetration by USA300 strains of MRSA [36]. Whether this was the 
Table 1 Infection due to methicillin-resistant Staphylococcus aureus in nursing homes

\begin{tabular}{|c|c|c|c|c|c|c|c|c|c|c|}
\hline \multicolumn{2}{|l|}{ Study } & \multirow{2}{*}{$\begin{array}{l}\text { Facility } \\
\text { Bed-Size }\end{array}$} & \multirow[t]{2}{*}{ Resident-Months } & \multirow[t]{2}{*}{ Total } & \multicolumn{5}{|c|}{ No. of Infections } & \multirow[t]{2}{*}{ Attributable Deaths } \\
\hline Author & Year & & & & SSTI & UTI & Pneumonia & $\begin{array}{l}\text { Bacteremia / } \\
\text { Sepsis }\end{array}$ & Other & \\
\hline Bradley [16•] & 1991 & 120 & 1,228 & 9 & 6 & - & 1 & 1 & 3 & 0 \\
\hline Muder [15•] & 1991 & 432 & 1,561 & 20 & NR & NR & NR & NR & NR & NR \\
\hline Spindel [106] & 1995 & 120 & 6,712 & 28 & 9 & 5 & 5 & 2 & 7 & 3 \\
\hline Mulhausen [18] & 1996 & $120^{\mathrm{a}}$ & 2,436 & 8 & 1 & 2 & 1 & 3 & 1 & 0 \\
\hline Lee [107] & 1997 & 149 & 1,788 & 14 & 4 & 5 & 2 & NR & 3 & NR \\
\hline Manzur [44] & 2011 & 100 & 6,132 & 14 & NR & NR & NR & NR & NR & 0 \\
\hline Shurland [39] & 2011 & $135^{\mathrm{b}}$ & 11,015 & 101 & NR & NR & NR & NR & NR & NR \\
\hline Totals & & & 30,872 & 194 & 20 & 12 & 9 & 6 & 14 & 3 \\
\hline Outcome per Resident-Year ${ }^{\mathrm{c}}$ & & & & 7.5 & 1.5 & 0.9 & 0.6 & 0.4 & 1.0 & 0.2 \\
\hline
\end{tabular}

SSTI skin and soft tissue infection; UTI urinary tract infection; NR not reported

${ }^{\text {a }} 4$ facilities with bed-sizes $=120$ (1) and 125 (3) included in this study

${ }^{\mathrm{b}} 2$ facilities with bed-sizes $=120$ and 150 included in this study

${ }^{\mathrm{c}}$ Calculated using reported resident-months observed for eligible outcomes. If a study did not specify specific types of infections or numbers of attributable deaths, then the resident-months observed in study were excluded from the denominator values used to calculate measure

result of changes in culturing practices or a true increase in the number of skin and soft infections in this facility is not clear. In contrast, a retrospective cohort study of residents colonized with USA300 or non-USA300 strains of MRSA did not identify any substantive differences in risk of infection between these two groups although the numbers of MRSA infections in both groups were higher as compared to residents who were $\operatorname{MRSA}(-)$ [39].

\section{Treatment of MRSA Infection in Nursing Homes}

Guidelines for the treatment of MRSA infections have recently been published [46••] and the management principles of the types of infections most commonly encountered in the NH are summarized in Table 2. While many NHs currently have the capacity to administer parenteral therapy onsite, this review assumes that these services are not commonly available and will instead focus on the management of less severe forms of infection assuming that more severe forms (e.g., pneumonia and bacteremia) will be managed in the acute care setting under the direction of a provider with infectious disease specialty experience.

As noted, skin and soft tissue infections (SSTI) are the most common manifestation of MRSA infection in NHs. These infections are heterogeneous in their presentation but it is useful to consider two subtypes: (1) SSTI associated with previously intact skin integrity (e.g., furuncle, carbuncle and purulent cellulitis) and (2) SSTI associated with compromised skin integrity (e.g., infected pressure ulcers, diabetic foot ulcers, device insertion site or surgical site infection). It is important to note that it is uncommon for MRSA to present as non-purulent cellulitis. $\beta$-hemolytic streptococci are the predominant cause of these presentations [47] and empiric treatment for MRSA is not routinely indicated, even in those residents with a prior history of MRSA colonization or infection [46••].

The mainstay of managing MRSA SSTIs associated with previously intact skin is incision and drainage of the purulent fluid collection. Warm compresses may be sufficient for the management of small furuncles $(<1 \mathrm{~cm})$ but most cutaneous abscesses of larger size should be incised using a combination of scalpel and blunt dissection followed by packing to facilitate drainage of the involved lesion [48]. Incision and drainage alone may be sufficient for moderately-sized lesions $(\leq 5 \mathrm{~cm})[49,50]$ but should be combined with antibiotic therapy in residents with larger lesions, systemic signs of infection (e.g., fever), lesions involving difficult to drain anatomical locations (e.g., face or genitalia), or those patients with significant comorbidity or frailty (e.g., extremes of age or diabetes with end-organ complications) [46••]. The oral tetracyclines (doxycycline and minocycline) or trimethoprim-sulfamethoxazole (TMP-SMX) are generally active against HA-MRSA and CA-MRSA while the activity of clindamycin against HA-MRSA strains is less predictable. It is important to note that TMP-SMX can interact with inhibitors of the renin-angiotensin system to cause clinical significant hyperkalemia and residents receiving both of these medications should be monitored closely. Linezolid is another oral treatment option but this medication is quite expensive and carries a significant risk of inducing a serotonin syndrome in those residents receiving selective serotonin reuptake inhibitors as well as serious myelosuppression when administered for more than two weeks. 
The management of MRSA SSTIs associated with compromised skin integrity is more complex and the interested reader is referred to excellent reviews and guidelines on the treatment of infected pressure wounds [51•] and diabetic foot ulcers [52•]. Chronic wounds will always grow bacteria and decisions to initiate therapy should be based on the presence of localizing and systemic signs of infection rather than the results of cultures. In residents where infection is suspected, the wound should be sharply debrided to remove necrotic debris before any cultures are performed, as cultures of wound slough are not indicative of the organism(s) causing symptoms and will lead to unnecessarily broad therapy. Tissue biopsy is the gold standard

Table 2 Management of common types of MRSA infection in nursing homes

\begin{tabular}{|c|c|c|c|c|}
\hline \multirow[t]{2}{*}{ Condition } & \multirow{2}{*}{$\begin{array}{l}\text { Non-Antibiotic } \\
\text { Management Issues }\end{array}$} & \multicolumn{2}{|c|}{ Antibiotic Management Issues } & \multirow[t]{2}{*}{ Duration of Therapy } \\
\hline & & Agent & Comments & \\
\hline \multicolumn{5}{|c|}{ Skin \& Soft Tissue Infection (SSTI) } \\
\hline $\begin{array}{l}\text { Involving previously intact skin } \\
\text { (purulent cellulitis) }\end{array}$ & - Incision and drainage & $\begin{array}{l}\text { Clindamycin } \\
300-450 \mathrm{mg} \\
\text { PO TID }\end{array}$ & $\begin{array}{l}\text { - Higher risk of Clostridium } \\
\text { difficile infection }\end{array}$ & $\begin{array}{l}\text { 7-14 days based on rapidity of } \\
\text { clinical response }\end{array}$ \\
\hline \multirow[t]{5}{*}{$\begin{array}{l}\text { Involving previously } \\
\text { compromised skin integrity } \\
\text { (infected pressure ulcers and } \\
\text { diabetic foot ulcers) }\end{array}$} & $\begin{array}{l}\text { - Debride necrotic } \\
\text { debris }\end{array}$ & $\begin{array}{l}\text { TMP-SMX 1- } \\
2 \text { DS tabs PO } \\
\text { BID }\end{array}$ & $\begin{array}{l}\text { - Combine with oral beta-lactam } \\
\text { (e.g., dicoloxacillin) if concern } \\
\text { for superimposed streptococcal } \\
\text { infection }\end{array}$ & \\
\hline & $\begin{array}{l}\text { - Culture wound base } \\
\text { by curettage or } \\
\text { modified Levine } \\
\text { technique }\end{array}$ & & $\begin{array}{l}\text { - Watch for hyperkalemia when } \\
\text { combined with inhibitors of the } \\
\text { renin-angiotensin system }\end{array}$ & \\
\hline & $\begin{array}{l}\text { - Assess for vascular } \\
\text { insufficiency }\end{array}$ & $\begin{array}{l}\text { Doxycycline } \\
100 \mathrm{mg} \text { PO } \\
\text { BID }\end{array}$ & $\begin{array}{l}\text { - Combine with oral beta-lactam } \\
\text { (e.g., dicoloxacillin) if concern } \\
\text { for superimposed streptococcal } \\
\text { infection }\end{array}$ & \\
\hline & $\begin{array}{l}\text { - Pressure offload } \\
\text { affected area }\end{array}$ & $\begin{array}{l}\text { Minocycline } \\
200 \mathrm{mg} \mathrm{x} 1 \\
\text { then } 100 \mathrm{mg} \\
\text { PO BID }\end{array}$ & $\begin{array}{l}\text { - Combine with oral beta-lactam } \\
\text { (e.g., dicoloxacillin) if concern } \\
\text { for superimposed streptococcal } \\
\text { infection }\end{array}$ & \\
\hline & $\begin{array}{l}\text { Provide good local } \\
\text { wound care }\end{array}$ & $\begin{array}{l}\text { Linezolid } \\
600 \mathrm{mg} \text { PO } \\
\text { BID }\end{array}$ & $\begin{array}{l}\text { - Very expensive } \\
\text { - Risk of serotonin syndrome } \\
\text { when combined with selective } \\
\text { serotonin reuptake inhibitors } \\
\text { (SSRIs) } \\
\text { - Risk of myelosuppression when } \\
\text { administered for }>2 \text { weeks }\end{array}$ & \\
\hline Urinary Tract Infection & $\begin{array}{l}\text { - Replace indwelling } \\
\text { urinary catheters if } \\
\text { in place for more } \\
\text { than } 2 \text { weeks }\end{array}$ & $\begin{array}{l}\text { TMP-SMX 1- } \\
2 \text { DS tabs PO } \\
\text { BID } \\
\text { Doxycycline } \\
100 \mathrm{mg} \text { PO } \\
\text { BID } \\
\text { Minocycline } \\
200 \mathrm{mg} \mathrm{x} \mathrm{1,} \\
\text { then } 100 \mathrm{mg} \\
\text { PO BID } \\
\text { Nitrofurantoin } \\
50-100 \mathrm{mg} \\
\text { PO BID }\end{array}$ & $\begin{array}{l}\text { - Watch for hyperkalemia when } \\
\text { combined with inhibitors of the } \\
\text { renin-angiotensin system } \\
\text { - Do not use if there is a } \\
\text { suspicion of upper urinary tract } \\
\text { infection } \\
\text { - Do not use in residents with } \\
\mathrm{CrCl}<40 \mathrm{~mL} / \mathrm{min}\end{array}$ & $\begin{array}{l}7-14 \text { days based on rapidity of } \\
\text { clinical response. Shorter courses } \\
\text { safe in residents with rapid } \\
\text { clinical responses. }\end{array}$ \\
\hline Pneumonia & $\begin{array}{l}\text { - An uncommon cause } \\
\text { of antibiotic regimens }\end{array}$ & $\begin{array}{l}\text { of infection that is } \\
\text { used to treat pne }\end{array}$ & $\begin{array}{l}\text { s managed within the nursing home } \\
\text { eumonia in the nursing home. }\end{array}$ & MRSA should not be a routine part \\
\hline Tracheobronchitis & $\begin{array}{l}\text { - The management of } \mathrm{r} \\
\text { consultation with a } \mathrm{sp}\end{array}$ & $\begin{array}{l}\text { esidents with rect } \\
\text { ecialist in infecti }\end{array}$ & $\begin{array}{l}\text { urrent episodes of tracheobronchitis } \\
\text { ous diseases or pulmonary medicin }\end{array}$ & $\begin{array}{l}\text { is challenging and may require } \\
\text { e. }\end{array}$ \\
\hline
\end{tabular}


method for isolating the pathogens primarily responsible for wound infection but is uncommonly performed in the $\mathrm{NH}$ setting. Tissue curettage of the wound base (after debridement of necrotic debris) or the modified Levine technique [53] are more accessible options that provide results similar to those achieved by tissue biopsy. Residents with infected wounds should be assessed for the presence of underlying ischemia and treatment should focus on pressure offloading the involved area and good wound care. Oral antibiotic therapy is reasonable in residents with mild presentations. Therapy should empirically target MRSA in residents with a prior history of MRSA or a recent wound culture positive for this organism and should also provide activity against streptococci as most residents will have a polymicrobial infection (Table 2). Oral therapy should be administered for a discrete duration (5-14 days) and residents who fail to respond clinically should be evaluated for a more complicated process (e.g., critical tissue ischemia, unrecognized soft tissue abscess or osteomyelitis).

MRSA is an uncommon cause of urinary tract infection (UTI) and is almost exclusively seen in residents with chronic indwelling catheters [54]. Bacteriuria is nearly universal in these individuals and a decision to initiate treatment should be driven by the presence of symptoms rather than by results of urinalyses and culture [55 ]. Treatment of asymptomatic bacteriuria in these individuals should only be performed prior to urological procedures. The management of residents with symptomatic UTI caused by MRSA involves replacement of the indwelling urinary catheter (for devices that have been in place for $>2$ weeks) [56] and systemic antibiotic therapy. There is limited data on the effectiveness of oral antibiotics for the treatment of UTI caused by MRSA and is not addressed in the Infectious Disease Society of America MRSA guidelines [46]. However, the United Kingdom MRSA guidelines do recommend that residents with infection involving the lower urinary tract can be treated with TMP-SMX, an oral tetracyclinederivative (doxycycline or minocycline) or nitrofurantoin [57]. Nitrofurantoin should not be used in residents with creatinine clearance $<40 \mathrm{~mL} / \mathrm{min}$ and is not effective in infections involving the upper urinary tract infection. In this latter situation, parenteral regimens are generally required. The ultimate length of therapy for UTI caused by MRSA is similarly unclear, but should be continued for at least 7 days and generally not for more than 14 days.

MRSA is a reasonably common cause of pneumonia among $\mathrm{NH}$ residents admitted to the hospital, particularly those who are admitted to the intensive care unit [58]. Management of pneumonia in the $\mathrm{NH}$ is often done without the benefit of respiratory cultures and a paucity of data on the microbiology of pneumonia managed in this setting make it difficult to determine the extent to which MRSA should be considered when selecting empiric antibiotic regimens in the $\mathrm{NH}$ [59]. Nevertheless, a retrospective study of $334 \mathrm{NH}$ residents hospitalized with pneumonia found no significant difference in mortality or time to clinical stability between residents treated with broad-spectrum (anti-MRSA) regimens versus those covered with regimens providing coverage for pathogens typical of community-acquired pneumonia [60]. This study excluded residents who had recently received antibiotic therapy and those who required ICU care, two factors known to be strongly associated with risk of infection with drug-resistant bacteria. It therefore seems reasonable to assume that most residents with pneumonia who are stable enough to remain in the $\mathrm{NH}$ do not have an infection caused by MRSA [61].

Residents with severe forms of chronic obstructive lung disease or those with a tracheostomy device may develop recurrent bouts of tracheobronchitis due to MRSA [62•]. These individuals often present with an increase in the purulence of respiratory secretions and more difficulty breathing without significant impairments in gas exchange or evidence of lung infiltrates by exam or chest $\mathrm{x}$-ray. These patients will often quickly respond to short courses (5-10 days) of oral antibiotic therapy (TMP-SMX or an oral tetracycline) but resistance emerges quickly with repeated antimicrobial exposures. Intermittent therapy with inhaled antibiotics (e.g., tobramycin) may reduce the frequency of exacerbations and limit the need for systemic antibiotic therapy although this has not been well studied. As a result, early consultation with a specialist in infectious diseases or pulmonary medicine is recommended in order to delay escalation to parenteral alternatives.

\section{Prevention of Infection in Residents with Known MRSA Colonization}

Studies performed in hospitalized patients have shown that $\sim 25 \%$ of long-term MRSA carriers will develop a serious infection in the year after identification of colonization [63]. Similar studies performed in NHs suggest the risk of subsequent infection is significantly lower; in the range of $10 \%$ [39], and many of these infections are mild in severity. Nevertheless, the morbidity and costs of treating these infections makes prevention of infection a worthwhile endeavor. At a conceptual level, avoidance of indwelling medical devices [64] and reducing skin barrier disruptions are two strategies that $\mathrm{NH}$ staff can be employ to reduce the risk of infection among residents with MRSA colonization. Elimination of MRSA carriage is another attractive intervention that has been of demonstrated benefit in surgical [65] and dialysis patients [66].

A variety of approaches for eradicating MRSA colonization have been attempted in NHs. An early study examining the impact of systemic antibiotic therapy failed to demonstrate an appreciable impact on MRSA colonization and high levels of resistance emerged as a result of therapy [67]. Based on these data, decolonization of MRSA using systemic antibiotic therapy alone is not recommended. Decolonization of MRSA(+) NH residents using the topical anti-infective mupirocin has been 
evaluated in number of studies. An early study using 7 days of intranasal mupirocin eliminated staphylococcal carriage (both MRSA and MSSA) in $91 \%$ of colonized residents in a VA LTCF, however, nearly half re-colonized within 2 months of treatment [68]. A subsequent nonrandomized study performed by the same group redemonstrated that intranasal mupirocin could rapidly eradicate nasal MRSA carriage [69]. However, the intrafacility prevalence of MRSA did not substantially drop until topical treatment of open wounds was combined with intranasal therapy. Despite the observed impact on MRSA prevalence, MRSA infection rates were not appreciably altered and the use of topical therapy was discontinued when significant levels of mupirocin resistance were observed in the study facility [69]. A randomized, placebo-controlled trial examining the impact of mupirocin on carriage of MRSA among residents in 2 LTCFs found that intranasal application eliminated carriage in $93 \%$ of subjects receiving active treatment [70]. Approximately one third of subjects who cleared recolonized within 90 days of therapy. While there was a trend towards a reduced rate of infection among those randomized to mupirocin, this did not reach statistical significance [70].

A number of nonexperimental studies examining the combined impact of topical and systemic therapy on MRSA carriage have been published [71-74]. Three of these studies were initiated in response to an outbreak and are susceptible to a number of methodological biases [75]. The remaining study, performed across $5 \mathrm{NHs}$ in the same geographic region found that a regimen of intranasal mupirocin, oral minocycline and rifampin as well as a daily $5 \%$ tea tree oil shower for 7 days followed a 5-day intranasal mupirocin plus daily showers with tea tree oil continuation phase administered once-monthly for 5 months reduced the prevalence of MRSA in participating NHs by $65 \%$ over a 12 -month period [74]. No data on the impact of the intervention on infection rates was provided and there was substantial numbers of residents $(\sim 1 / 3)$ who were lost to follow-up making it difficult to assess the impact of the intervention on individual resident outcomes.

Taken together, these data suggest that intranasal mupirocin, with or without adjunctive systemic antibiotic therapy, and bathing with anti-infective soap, can effect short-term eradication of MRSA colonization. The impact this intervention has on an individual resident's risk of infection and intra-facility rates of MRSA transmission remains undefined. Given the considerable potential for adverse effects from the agents used and the risk of promoting resistance, particularly to mupirocin, routine decolonization of MRSA(+) residents cannot be routinely recommended at this time [76].

\section{Prevention of MRSA Transmission in Nursing Homes}

A number of guidelines on controlling the spread of MRSA in healthcare facilities have been published [77-79]. These guidelines have generally approached control of MRSA from the hospital perspective. Guidelines that address the issue of MRSA in long-term care facilities have also been published by the Association for Professionals in Infection Control and Epidemiology [80 ${ }^{\bullet}$ and the California Department of Public Health [81•] although both are largely modeled after recommendations included in the 2006 Centers for Disease Control and Prevention multi-drug resistant organism (MDRO) guideline [78]. Control methods addressed in these guidelines include the role of hand hygiene, transmission-based precautions (i.e., isolation), room assignment, environmental cleaning, and the role of active surveillance to detect asymptomatic colonization. It is important to note that there is an appalling lack of evidence supporting most of the recommendations included in these guidelines [82] and there is substantial uncertainty about the degree to which any of these measures should be deployed in the NH setting.

While there are few NH-specific studies upon which to draw from [82], there is sufficient biological and indirect evidence to support building an MRSA control program around three basic infection control practices: (1) enhancing staff (and perhaps resident) adherence to hand hygiene; (2) enhancing staff adherence to standard precautions, and (3) enhancing care and maintenance of wounds and indwelling medical devices $[64,83 \bullet, 84]$. The transmission of drugresistant bacteria (including MRSA) remained unchanged on a LTCF unit after liberalizing contact isolation of colonized residents when coupled with an intervention to enhance the hand hygiene of staff (routine gloving prior to anticipated resident contact) [23]. Unfortunately, the observed impact of horizontal infection control programs on MRSA and other infectious disease outcomes documented in other published studies have been largely disappointing [85-87]. Education, a notoriously ineffective method for eliciting sustained changes in behavior, was the predominant method used for effecting improved adherence to hygienic practices in these studies. While none of these studies demonstrated a significant impact on the prevalence of MRSA or other types of $\mathrm{NH}$-acquired infections, only one of the studies sought to measure the impact of education on the targeted behavior [87]. Given these methodological weaknesses, it is hard to draw firm conclusions from these studies and, more than anything, suggest a need for more research on ways to more effectively improve staff infection control behaviors in NHs. Achieving advances in this area are particularly important as they would be expected to not only improve facility rates of MRSA but rates of infections caused by other epidemiologically important pathogens (e.g., C. difficile) $[88,89]$.

Contact isolation of individuals colonized with MRSA is a widely used strategy to control the spread of MRSA within hospitals [75]. The effectiveness of this strategy in NHs is more controversial $[90,91]$. The mechanisms of MRSA transmission in NHs are largely unknown and an individual resident's risk of 
transmitting MRSA to others is likely highly variable. Indeed, it seems reasonable to assume that most MRSA $(+)$ residents pose minimal risk of transmitting MRSA to others based on studies of transmission rates between roommates [16•, 17, 24•, 27•]. Importantly, studies in hospitals have shown that patients under contact isolation experience higher rates of depression and medical errors and have less frequent contact with healthcare workers [92-94]. While similar studies have not been performed in the $\mathrm{NH}$ setting, there is reason to believe that the adverse consequences of contact isolation will be augmented in this setting [91]. Consequently, the untargeted isolation of residents colonized with MRSA may have a limited impact on rates of transmission while unnecessarily exposing them to the adverse consequences of this social distancing intervention. In light of these concerns, it seems prudent to approach untargeted application of contact isolation in the $\mathrm{NH}$ with some caution. Stratifying transmission-based precautions based on a resident's perceived risk of transmission is a compromise strategy currently employed in VA LTCFs [95] and an approach advocated by the California Department of Public Health [81•] in order to maximize resident opportunities for social interaction while minimizing their risk of transmitting MRSA to others. While individualizing resident social distancing measures based on perceived risk of MRSA transmission faces some practical barriers to implementation, it is a process that is consistent with other care plan activities currently performed in NHs (e.g., falls and pressure sore prevention). An example of how this might be operationalized in a $\mathrm{NH}$ is provided in the figure (Fig. 1). Future studies should seek to examine the practicality and effectiveness of this and other approaches [83॰].

The limited number of single rooms in most NHs creates challenges for placement of residents colonized with MRSA and colonization status has been identified as a reason for delayed transfers from acute care facilities $[96,97]$. While it is reasonable to preferentially place $\operatorname{MRSA}(+)$ residents in single rooms when available, a strict policy of avoiding placement with an MRSA(-) individual seems misguided based on the limited number of MRSA transmissions identified in studies of MRSA discordant roommates $[16 \bullet, 17,24 \bullet, 27 \bullet]$. Utilizing the approach outlined in the figure, $\operatorname{MRSA}(+)$ residents without an active infection and without risk factors for transmission could be placed with an MRSA(-) resident if a single room or vacancy with another $\operatorname{MRSA}(+)$ resident is available. In this manner, single rooms in NHs would be reserved primarily for
Fig. 1 Proposed strategy for differential application of transmission-based precautions in the nursing home based on a resident's baseline risk of transmitting methicillinresistant Staphylococcus aureus (MRSA). * Transmission risk factors: (1) open wound; (2) exposed indwelling medical device; and (3) impaired cognitive status. $* *$ Instructions to follow: (1) don clean clothes prior to leaving room; (2) performs hand hygiene before contact with other residents; 3 ) covers cough and sneezes; (4) keeps wounds and devices covered; and (5) ability to clean up after self. ๆ Enhanced standard precautions: identical to standard precautions with the exception that medical equipment is dedicated to the resident's room and residents are preferentially placed in single rooms or with other $\operatorname{MRSA}(+)$ residents before placement in a room with an MRSA(-) resident

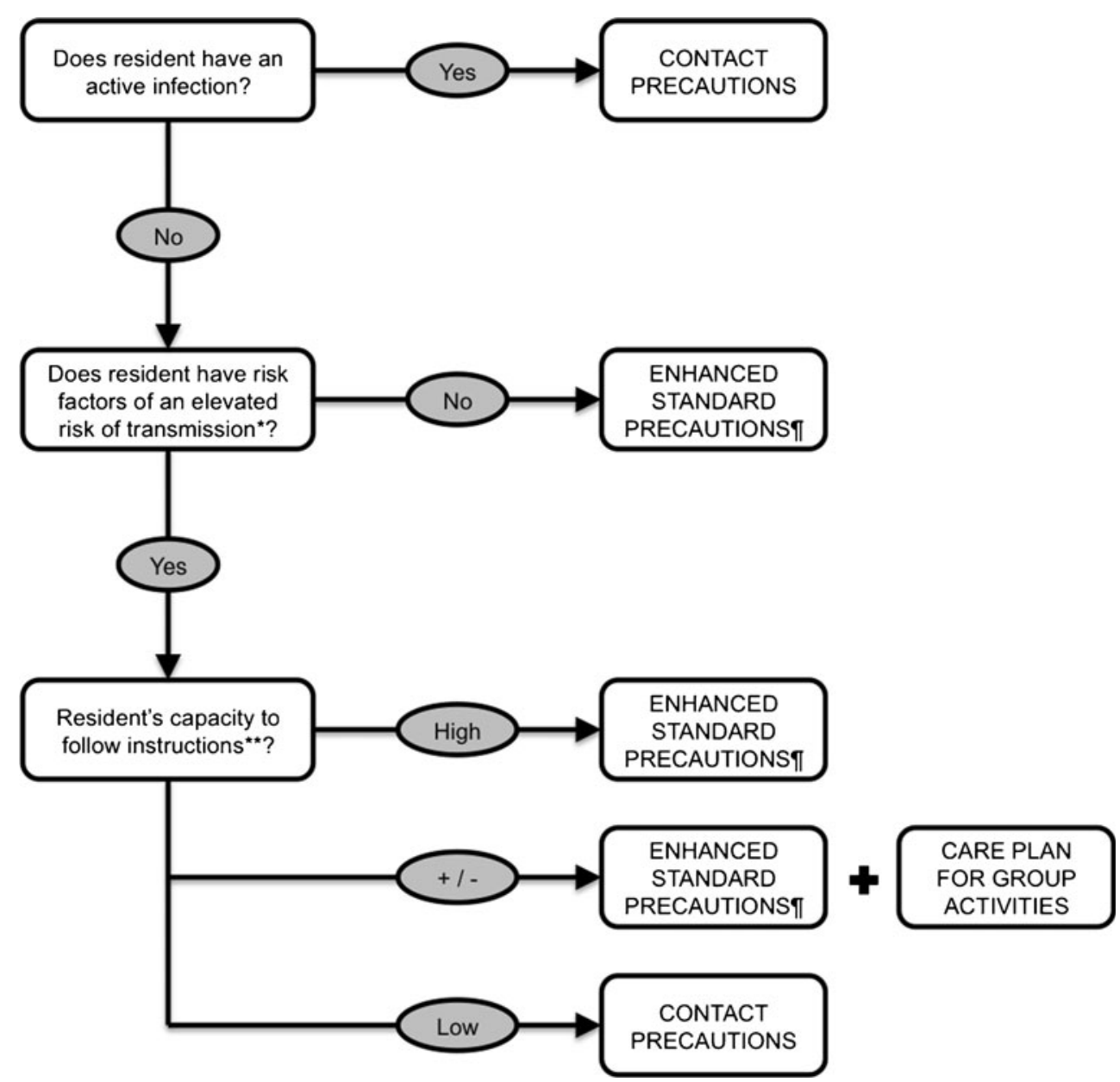


the small population of $\operatorname{MRSA}(+)$ residents who have an elevated risk of transmitting MRSA to others.

Other strategies that may play a role in preventing the transmission of MRSA include active surveillance, enhanced environmental cleaning, and improvements in antibiotic stewardship. Active surveillance to detect asymptomatic MRSA colonization has been advocated as a method to control the transmission of MRSA in healthcare settings [77]. Despite well publicized successes [98-100], active surveillance to detect asymptomatic MRSA colonization remains a controversial topic in hospitals [88]. Given an absence of data clearly demonstrating that existing decolonization strategies can reduce intrafacility transmission of MRSA, active surveillance to detect asymptomatic MRSA colonization would appear to have limited utility in NHs at the current time [83॰]. Studies have shown the capacity for MRSA to persist on surfaces for prolonged periods of time and improvements in environmental cleaning have been associated with reduced risk of MRSA transmission in the ICU setting [101]. MRSA contamination of environmental surfaces is common in NHs and higher levels of contamination have been correlated with reduced frequency and duration of cleaning and were associated with a surrogate of MRSA transmission in at least one study [102]. These data suggest that improving environmental cleaning procedures through standardized protocols to target high-touch surfaces in common areas may have a role in the institutional control of MRSA but further studies are needed before NHs devote considerable resources to these activities. Recent antibiotic exposure is associated with acquisition of MRSA in the $\mathrm{NH}$ $\left[24^{\bullet}, 27 \cdot\right]$ and up to $70 \%$ of antibiotic use in in these facilities may be inappropriate [103]. Despite the challenges in changing deeply engrained prescribing behaviors in NHs, improving the use of antibiotics has the potential to influence a number of resident outcomes. Consequently, improving antibiotic stewardship should be a high priority in NHs [103].

\section{Conclusion}

MRSA is widespread in NHs and these facilities appear to play an important role in amplifying the regional burden of MRSA $[104,105]$. Nevertheless, there is a limited understanding of the mechanisms by which MRSA is spread within the NH and most residents remain asymptomatically colonized. Given an absence of impact on important resident health outcomes, reducing MRSA colonization in a $\mathrm{NH}$ primarily benefits the hospitals within its referral network. While this is an important population health goal, it should not come at the expense of resident quality-of-life. Until additional evidence demonstrating the safety and effectiveness of aggressive infection control measures (e.g., strict application of contact isolation, active surveillance, decolonization) emerges, NHs should primarily focus on improving staff adherence to basic hygienic practices (hand hygiene, standard precautions) and individualizing transmission-based precautions in order to minimize their adverse impact on resident quality-of-life. Novel horizontal approaches that reduce microbial contamination of environmental surfaces and minimize inappropriate antibiotic use in $\mathrm{NHs}$ have the potential to impact resident outcomes associated with other epidemiologically important pathogens ( $C$. difficile) and more research is needed in order to determine how these strategies can be more effectively introduced into these facilities.

Acknowledgments Christopher J. Crnich is supported by grants from the VA Office of Geriatrics and Extended Care (T-21 grant), the Wisconsin Civil Monetary Penalty Fund (research grant).

\section{Compliance with Ethics Guidelines}

Conflict of Interest Christopher J. Crnich has received compensation from Covance for serving on a data safety monitoring board, and was reimbursed for travel/accommodations expenses by IDWeek (2012).

Human and Animal Rights and Informed Consent This article does not contain any studies with human or animal subjects performed by any of the authors.

\section{References}

Papers of particular interest, published recently, have been highlighted as:

- Of importance

-• Of major importance

1. - Klein E, Smith D, Laxminarayan R. Hospitalizations and deaths caused by methicillin-resistant Staphylococcus aureus, United States, 1999-2005. Emerging Infect Dis. 2007;13:1840-6. These three articles nicely summarize patters of infections caused by methicillin-resistant Staphylococcus aureus (MRSA) in the United States over the past decade.

2. - Klevens R, Morrison M, Nadle J, et al. Invasive methicillinresistant Staphylococcus aureus infections in the United States. JAMA. 2007;298:1763-71. These three articles nicely summarize patters of infections caused by methicillin-resistant Staphylococcus aureus (MRSA) in the United States over the past decade.

3. - Elixhauser A, Steiner C. Infections with Methicillin-resistant Staphylococcus Aureus (MRSA) in U.S. Hospitals, 1993-2005. Healthcare Cost and Utilization Project: Statistical Brief \#35. Agency for Healthcare Research and Quality. 2007. These three articles nicely summarize patters of infections caused by methicillinresistant Staphylococcus aureus (MRSA) in the United States over the past decade.

4. Noskin GA, Rubin RJ, Schentag JJ, et al. National trends in Staphylococcus aureus infection rates: impact on economic burden and mortality over a 6-year period (1998-2003). Clin Infect Dis. 2007; 45:1132-40.

5. Kallen AJ, Mu Y, Bulens S, et al. Health care-associated invasive MRSA infections, 2005-2008. JAMA. 2010;304:641-8.

6. Martin GS, Mannino DM, Moss M. The effect of age on the development and outcome of adult sepsis. Crit Care Med. 2006;34:15-21. 
7. Christensen KLY, Holman RC, Steiner CA, Sejvar JJ, Stoll BJ, Schonberger LB. Infectious disease hospitalizations in the United States. Clin Infect Dis. 2009;49:1025-35.

8. Fukuta Y, Cunningham CA, Harris PL, Wagener MM, Muder RR. Identifying the Risk Factors for Hospital-Acquired MethicillinResistant Staphylococcus aureus (MRSA) Infection among Patients Colonized with MRSA on Admission. Infect Control Hosp Epidemiol. 2012;33:1219-25.

9. Schoevaerdts D, Agelas J-P, Ingels M-G, et al. Health outcomes of older patients colonized by multi-drug resistant bacteria (MDRB): a one-year follow-up study. Arch Gerontol Geriatr. 2013;56:231-6.

10. Stone $\mathrm{N}$, Lewis $\mathrm{D}$, Lowery $\mathrm{H}$, et al. Importance of bacterial burden among methicillin-resistant Staphylococcus aureus carriers in a longterm care facility. Infect Control Hosp Epidemiol. 2008;29:143-8.

11. Furuno JP, Hebden JN, Standiford HC, et al. Prevalence of methicillin-resistant Staphylococcus aureus and Acinetobacter baumannii in a long-term acute care facility. Am J Infect Control. 2008;36:468-71.

12. Reynolds C, Quan V, Kim D, et al. Methicillin-resistant Staphylococcus aureus (MRSA) carriage in 10 nursing homes in Orange County, California. Infect Control Hosp Epidemiol. 2011;32:91-3.

13. Crnich CJ, Duster M, Hess T, Zimmerman DR, Drinka P. Antibiotic resistance in non-major metropolitan skilled nursing facilities: prevalence and interfacility variation. Infect Control Hosp Epidemiol. 2012;33:1172-4.

14. Strausbaugh LJ, Jacobson C, Sewell DL, Potter S, Ward TT. Methicillin-resistant Staphylococcus aureus in extended-care facilities: experiences in a Veterans' Affairs nursing home and a review of the literature. Infect Control Hosp Epidemiol. 1991;12:36-45.

15. - Muder R, Brennen C, Wagener M, et al. Methicillin-resistant staphylococcal colonization and infection in a long-term care facility. Ann Intern Med. 1991;114:107-12. These studies are two of the best examinations of the natural history of MRSA in nursing homes with a stable (non-outbreak) prevalence of MRSA.

16. • Bradley S, Terpenning M, Ramsey M, et al. Methicillin-resistant Staphylococcus aureus: colonization and infection in a long-term care facility. Ann Intern Med. 1991;115:417-22. These studies are two of the best examinations of the natural history of MRSA in nursing homes with a stable (non-outbreak) prevalence of MRSA.

17. Hsu CC. Serial survey of methicillin-resistant Staphylococcus aureus nasal carriage among residents in a nursing home. Infect Control Hosp Epidemiol. 1991;12:416-21.

18. Mulhausen PL, Harrell LJ, Weinberger M, Kochersberger GG, Feussner JR. Contrasting methicillin-resistant Staphylococcus aureus colonization in Veterans Affairs and community nursing homes. Am J Med. 1996;100:24-31.

19. • Mody L, Kauffman CA, Donabedian S, Zervos M, Bradley SF. Epidemiology of Staphylococcus aureus colonization in nursing home residents. Clin Infect Dis. 2008;46:1368-73. A good example of the risk factors and different patterns of MRSA colonization of residents in nursing homes.

20. Manzur A, Gudiol F. Methicillin-resistant Staphylococcus aureus in long-term-care facilities. Clin Microbiol Infect. 2009;15 Suppl 7:2630.

21. Storch GA, Radcliff JL, Meyer PL, Hinrichs JH. Methicillin-resistant Staphylococcus aureus in a nursing home. Infect Control. 1987;8:24-9.

22. Thomas JC, Bridge J, Waterman S, Vogt J, Kilman L, Hancock G. Transmission and control of methicillin-resistant Staphylococcus aureus in a skilled nursing facility. Infect Control Hosp Epidemiol. 1989;10:106-10.

23. Trick W, Weinstein R, Demarais P, et al. Comparison of routine glove use and contact-isolation precautions to prevent transmission of multidrug-resistant bacteria in a long-term care facility. J Am Geriatr Soc. 2004;52:2003-9.
24. - Furuno JP, Shurland SM, Zhan M, et al. Comparison of the Methicillin-Resistant Staphylococcus aureus Acquisition among Rehabilitation and Nursing Home Residents. Infect Control Hosp Epidemiol. 2011;32:244-9. A nicely done study examining differences in risk factors for the acquisition of MRSA among residents on postacute versus long-term stay unites in three different long-term care facilities.

25. Fisch J, Lansing B, Wang L, et al. New acquisition of antibioticresistant organisms in skilled nursing facilities. J Clin Microbiol. 2012;50:1698-703

26. Murphy CR, Quan V, Kim D, et al. Nursing home characteristics associated with methicillin-resistant Staphylococcus aureus (MRSA) Burden and Transmission. BMC Infect Dis. 2012;12:269.

27. - Stone ND, Lewis DR, Johnson TM, et al. Methicillin-Resistant Staphylococcus aureus (MRSA) Nasal Carriage in Residents of Veterans Affairs Long-Term Care Facilities: Role of Antimicrobial Exposure and MRSA Acquisition. Infect Control Hosp Epidemiol. 2012;33:551-7. A well-designed epidemiological study of MRSA acquisition performed in three different long-term care facilities. A major finding of this study was the strong association between recent antibiotic use and acquisition of MRSA.

28. Elixhauser A, Steiner C. Statistical brief \#35: infection with methicillin-resistant Staphylococcus aureus (MRSA) in U.S. hospitals, 1993-2005. 2009;

29. Chambers HF, Deleo FR. Waves of resistance: Staphylococcus aureus in the antibiotic era. Nat Rev Microbiol. 2009;7:629-41.

30. Klevens R, Edwards J, Richards C, et al. Estimating health careassociated infections and deaths in U.S. hospitals, 2002. Public Health Rep. 2007;122:160-6.

31. Deleo FR, Otto M, Kreiswirth BN, Chambers HF. Communityassociated meticillin-resistant Staphylococcus aureus. Lancet. 2010;375:1557-68.

32. Maree CL, Daum RS, Boyle-Vavra S, Matayoshi K, Miller LG. Community-associated methicillin-resistant Staphylococcus aureus isolates causing healthcare-associated infections. Emerging Infect Dis. 2007;13:236-42.

33. Carleton HA, Diep BA, Charlebois ED, Sensabaugh GF, Perdreau-Remington F. Community-adapted methicillin-resistant Staphylococcus aureus (MRSA): population dynamics of an expanding community reservoir of MRSA. J Infect Dis. 2004;190:1730-8.

34. Shurland SM, Stine OC, Venezia RA, et al. Colonization sites of USA300 methicillin-resistant Staphylococcus aureus in residents of extended care facilities. Infect Control Hosp Epidemiol. 2009;30:313-8.

35. Murphy CR, Hudson LO, Spratt BG, et al. Predicting High Prevalence of Community Methicillin-Resistant Staphylococcus aureus Strains in Nursing Homes. Infect Control Hosp Epidemiol. 2013;34:325-6.

36. Tattevin P, Diep BA, Jula M, Perdreau-Remington F. Methicillinresistant Staphylococcus aureus USA300 clone in long-term care facility. Emerging Infect Dis. 2009;15:953-5.

37. Crnich CJ, Duster M, Hess T, Zimmerman DR, Drinka P. Antibiotic resistance in non-major metropolitan nursing homes: prevalence and inter-facility variation. Infect Control Hosp Epidemiol under revision.

38. Safdar N, Bradley EA. The risk of infection after nasal colonization with Staphylococcus aureus. Am J Med. 2008;121:310-5.

39. Shurland SM, Stine OC, Venezia RA, et al. USA300 methicillinresistant S. aureus (USA300 MRSA) colonization and the risk of MRSA infection in residents of extended-care facilities. Epidemiol Infect. 2011:1-10.

40. Bradley EH, Holmboe ES, Mattera JA, Roumanis SA, Radford MJ, Krumholz HM. A qualitative study of increasing betablocker use after myocardial infarction: Why do some hospitals succeed? JAMA. 2001;285:2604-11. 
41. Muder R, Brennen C, Goetz A, Wagener M, Rihs J. Association with prior fluoroquinolone therapy of widespread ciprofloxacin resistance among gram-negative isolates in a Veterans Affairs medical center. Antimicrob Agents Chemother. 1991;35:256-8.

42. Niclaes L, Buntinx F, Banuro F, Lesaffre E, Heyrman J. Consequences of MRSA carriage in nursing home residents. Epidemiol Infect. 1999;122:235-9.

43. Suetens C, Niclaes L, Jans B, et al. Methicillin-Resistant Staphylococcus aureus Colonization Is Associated with Higher Mortality in Nursing Home Residents with Impaired Cognitive Status. J Am Geriatr Soc. 2006;54:1854-60.

44. Manzur A, DE Gopegui ER, Dominguez M, et al. Clinical significance of methicillin-resistant Staphylococcus aureus colonization in residents in community long-term-care facilities in Spain. Epidemiol Infect. 2011:1-7.

45. Capitano B, Leshem O, Nightingale C, Nicolau D. Cost effect of managing methicillin-resistant Staphylococcus aureus in a longterm care facility. J Am Geriatr Soc. 2003;51:10-6.

46. •• Liu C, Bayer A, Cosgrove SE, et al. Clinical practice guidelines by the infectious diseases society of america for the treatment of methicillin-resistant Staphylococcus aureus infections in adults and children. Clin Infect Dis. 2011;52:e18-55. This is an excellent guideline summarizing the antimicrobial and non-antimicrobial management of different types of MRSA infections in both inpatient and outpatient settings. A must read for any clinician.

47. Jeng A, Beheshti M, Li J, Nathan R. The role of beta-hemolytic streptococci in causing diffuse, nonculturable cellulitis: a prospective investigation. Medicine. 2010;89:217-26.

48. Fitch MT, Manthey DE, McGinnis HD, Nicks BA, Pariyadath M. Videos in clinical medicine. Abscess incision and drainage. $\mathrm{N}$ Engl J Med. 2007;357:e20.

49. Rajendran PM, Young D, Maurer T, et al. Randomized, doubleblind, placebo-controlled trial of cephalexin for treatment of uncomplicated skin abscesses in a population at risk for community-acquired methicillin-resistant Staphylococcus aureus infection. Antimicrob Agents Chemother. 2007;51:4044-8.

50. Schmitz GR, Bruner D, Pitotti R, et al. Randomized controlled trial of trimethoprim-sulfamethoxazole for uncomplicated skin abscesses in patients at risk for community-associated methicillin-resistant Staphylococcus aureus infection. Ann Emerg Med. 2010;56:283-7.

51. - Livesley NJ, Chow AW. Infected pressure ulcers in elderly individuals. Clin Infect Dis. 2002;35:1390-6. These two guidelines provide an in-depth review of the management of patients with pressure ulcers and diabetic foot ulcers, two conditions that are ubiquitous in the long-term care setting.

52. - Lipsky BA, Berendt AR, Cornia PB, et al. Infectious Diseases Society of America clinical practice guideline for the diagnosis and treatment of diabetic foot infections. Clin Infect Dis. 2012;54:e132 73. These two guidelines provide an in-depth review of the management of patients with pressure ulcers and diabetic foot ulcers, two conditions that are ubiquitous in the long-term care setting.

53. Drinka P, Bonham P, Crnich CJ. Swab culture of purulent skin infection to detect infection or colonization with antibioticresistant bacteria. J Am Med Dir Assoc. 2012;13:75-9.

54. Muder RR, Brennen C, Rihs JD, et al. Isolation of Staphylococcus aureus from the urinary tract: association of isolation with symptomatic urinary tract infection and subsequent staphylococcal bacteremia. Clin Infect Dis. 2006;42:46-50.

55. - Hooton TM, Bradley SF, Cardenas DD, et al. Diagnosis, prevention, and treatment of catheter-associated urinary tract infection in adults: 2009 International Clinical Practice Guidelines from the Infectious Diseases Society of America. Clin Infect Dis. 2010;50:625-63. An exhaustively referenced evidence-based document on the management and prevention of urinary tract infections in adult patients, both those with and without indwelling urinary catheters.
56. Raz R, Schiller D, Nicolle LE. Chronic indwelling catheter replacement before antimicrobial therapy for symptomatic urinary tract infection. J Urol. 2000;164:1254-8.

57. Gould FK, Brindle R, Chadwick PR, et al. Guidelines (2008) for the prophylaxis and treatment of methicillin-resistant Staphylococcus aureus (MRSA) infections in the United Kingdom. J Antimicrob Chemother. 2009;63:849-61.

58. Kollef MH, Shorr A, Tabak YP, Gupta V, Liu LZ, Johannes RS. Epidemiology and outcomes of health-care-associated pneumonia: results from a large US database of culture-positive pneumonia. Chest. 2005;128:3854-62.

59. Drinka P, Niederman MS, El-Solh AA, Crnich CJ. Assessment of risk factors for multi-drug resistant organisms to guide empiric antibiotic selection in long term care: a dilemma. J Am Med Dir Assoc. 2011;12:321-5.

60. El-Solh AA, Akinnusi ME, Alfarah Z, Patel A. Effect of antibiotic guidelines on outcomes of hospitalized patients with nursing home-acquired pneumonia. J Am Geriatr Soc. 2009;57:1030-5.

61. Brito V, Niederman MS. Healthcare-associated pneumonia is a heterogeneous disease, and all patients do not need the same broad-spectrum antibiotic therapy as complex nosocomial pneumonia. Curr Opin Infect Dis. 2009;22:316-25.

62. - Crnich CJ, Drinka P. Medical device-associated infections in the long-term care setting. Infect Dis Clin North Am. 2012;26:14364. A nice review of the presentation and management of different types of device-related infections encountered in nursing homes.

63. Datta R, Huang SS. Risk of infection and death due to methicillin-resistant Staphylococcus aureus in long-term carriers. Clin Infect Dis. 2008;47:176-81.

64. Mody L, Bradley SF, Galecki A, et al. Conceptual model for reducing infections and antimicrobial resistance in skilled nursing facilities: focusing on residents with indwelling devices. Clin Infect Dis. 2011;52:654-61.

65. Bode LGM, Kluytmans JAJW, Wertheim HFL, et al. Preventing surgical-site infections in nasal carriers of Staphylococcus aureus. N Engl J Med. 2010;362:9-17.

66. Tacconelli E, Carmeli Y, Aizer A, Ferreira G, Foreman MG, D'Agata EMC. Mupirocin prophylaxis to prevent Staphylococcus aureus infection in patients undergoing dialysis: a meta-analysis. Clin Infect Dis. 2003;37:1629-38.

67. Strausbaugh LJ, Jacobson C, Sewell DL, Potter S, Ward TT. Antimicrobial therapy for methicillin-resistant Staphylococcus aureus colonization in residents and staff of a Veterans Affairs nursing home care unit. Infect Control Hosp Epidemiol. 1992;13:151-9.

68. Cederna JE, Terpenning MS, Ensberg M, Bradley SF, Kauffman CA. Staphylococcus aureus nasal colonization in a nursing home: eradication with mupirocin. Infect Control Hosp Epidemiol. 1990;11:13-6.

69. Kauffman CA, Terpenning MS, He X, et al. Attempts to eradicate methicillin-resistant Staphylococcus aureus from a long-term-care facility with the use of mupirocin ointment. Am J Med. 1993;94:371-8.

70. Mody L, Kauffman CA, McNeil SA, Galecki AT, Bradley SF. Mupirocin-based decolonization of Staphylococcus aureus carriers in residents of 2 long-term care facilities: a randomized, doubleblind, placebo-controlled trial. Clin Infect Dis. 2003;37:1467-74.

71. Simor AE, Augustin A, Ng J, Betschel S, McArthur M. Control of MRSA in a long-term care facility. Infect Control Hosp Epidemiol. 1994;15:69-70.

72. Kotilainen P, Routamaa M, Peltonen R, et al. Eradication of methicillin-resistant Staphylococcus aureus from a health center ward and associated nursing home. Arch Intern Med. 2001;161:859-63.

73. Harberg D. Society for Healthcare Epidemiology of America guideline approach works to control a methicillin-resistant Staphylococcus aureus outbreak. Infect Control Hosp Epidemiol. 2005;26:115-6.

74. Bowler WA, Bresnahan J, Bradfish A, Fernandez C. An integrated approach to methicillin-resistant Staphylococcus aureus 
control in a rural, regional-referral healthcare setting. Infect Control Hosp Epidemiol. 2010;31:269-75.

75. Cooper B, Stone S, Kibbler C, et al. Isolation measures in the hospital management of methicillin resistant Staphylococcus aureus (MRSA): systematic review of the literature. BMJ. 2004;329:533-40.

76. Bradley SF. Eradication or decolonization of methicillin-resistant Staphylococcus aureus carriage: what are we doing and why are we doing it? Clin Infect Dis. 2007;44:186-9.

77. Muto CA, Jernigan JA, Ostrowsky BE, et al. SHEA guideline for preventing nosocomial transmission of multidrug-resistant strains of Staphylococcus aureus and enterococcus. Infect Control Hosp Epidemiol. 2003;24:362-86.

78. Siegel JD, Rhinehart E, Jackson M, Chiarello L. Healthcare Infection Control Practices Advisory C. Management of multidrug-resistant organisms in health care settings, 2006. Am J Infect Control. 2007;35:S165-93.

79. Calfee DP, Salgado CD, Classen D, et al. Strategies to prevent transmission of methicillin-resistant Staphylococcus aureus in acute care hospitals. Infect Control Hosp Epidemiol. 2008;29:S62-80.

80. - Rebmann T, Aureden K. Association for Professionals in Infection Control and Epidemiology. Preventing methicillinresistant Staphylococcus aureus transmission in long-term care facilities: an executive summary of the APIC Elimination Guide. Am J Infect Control. 2011;39:235-8. Both of these references address issues of controlling the spread of MRSA in nursing homes and are an attempt to different from hospitals. While the recommendations have not been validated empirically, they are thoughtful reviews on the unique challenges that providers face in nursing homes.

81. - Cahill CK. Joint infection prevention and control guidelines: enhanced standard precautions (ESP) for California long-term care facilities. 2010. Available at: http:/www.cdph.ca.gov/programs/hai/ Documents/AFL10-27AttachmentIncluded.pdf. Accessed 8 April 2013. Both of these references address issues of controlling the spread of MRSA in nursing homes and are an attempt to different from hospitals. While the recommendations have not been validated empirically, they are thoughtful reviews on the unique challenges that providers face in nursing homes.

82. Hughes C, Smith M, Tunney M, Bradley MC. Infection control strategies for preventing the transmission of meticillin-resistant Staphylococcus aureus (MRSA) in nursing homes for older people. Cochrane Database Syst Rev. 2011;12, CD006354.

83. - Bradley SF. Methicillin-resistant Staphylococcus aureus: long-term care concerns. Am J Med. 1999;106:2S-10. discussion 48S-52S. A nice review on the issues germane to the control of MRSA in nursing homes. The author provides a nice conceptual overview that is somewhat different than the one proposed in this review.

84. Pittet D, Hugonnet S, Harbarth S, et al. Effectiveness of a hospital-wide programme to improve compliance with hand hygiene. Lancet. 2000;356:1307-12.

85. Baldwin NS, Gilpin DF, Tunney MM, et al. Cluster randomised controlled trial of an infection control education and training intervention programme focusing on meticillin-resistant Staphylococcus aureus in nursing homes for older people. J Hosp Infect. 2010;76:36-41.

86. Chami K, Gavazzi G, Bar-Hen A, et al. A short-term, multicomponent infection control program in nursing homes: a cluster randomized controlled trial. J Am Med Dir Assoc. 2012;13:569.e9-17.

87. Horner C, Wilcox M, Barr B, et al. The longitudinal prevalence of MRSA in care home residents and the effectiveness of improving infection prevention knowledge and practice on colonisation using a stepped wedge study design. BMJ Open. 2012;2:e000423.

88. Wenzel RP, Bearman G, Edmond MB. Screening for MRSA: a flawed hospital infection control intervention. Infect Control Hosp Epidemiol. 2008;29:1012-8.
89. Wenzel RP, Edmond MB. Infection control: the case for horizontal rather than vertical interventional programs. Int J Infect Dis. 2010;14 Suppl 4:S3-5.

90. Lee BY, Singh A, Bartsch SM, et al. The Potential Regional Impact of Contact Precaution Use in Nursing Homes to Control Methicillin-Resistant Staphylococcus aureus. Infect Control Hosp Epidemiol. 2013;34:151-60.

91. Crnich CJ, Drinka PJ. Predicting the impact of contact precautions on MRSA outcomes: caution up ahead. Infect Control Hosp Epidemiol. 2013;(in press).

92. Morgan DJ, Diekema DJ, Sepkowitz K, Perencevich EN. Adverse outcomes associated with Contact Precautions: a review of the literature. Am J Infect Control. 2009;37:85-93.

93. Day HR, Perencevich EN, Harris AD, et al. Do contact precautions cause depression? A two-year study at a tertiary care medical centre. J Hosp Infect. 2011;79:103-7.

94. Morgan DJ, Pineles L, Shardell M, et al. The effect of contact precautions on healthcare worker activity in acute care hospitals. Infect Control Hosp Epidemiol. 2013;34:69-73.

95. Office of Veteran Affairs. Guidelines for implementation of MRSA Prevention Initiative in the Community Living Centers (CLC). Veterans Health Administration. 2008.

96. Bryce EA, Tiffin SM, Isaac-Renton JL, Wright CJ. Evidence of delays in transferring patients with methicillin-resistant Staphylococcus aureus or vancomycin-resistant Enterococcus to long-term-care facilities. Infect Control Hosp Epidemiol. 2000;21:270-1.

97. Kreman T, Hu J, Pottinger J, Herwaldt LA. Survey of long-term-care facilities in Iowa for policies and practices regarding residents with methicillin-resistant Staphylococcus aureus or vancomycin-resistant enterococci. Infect Control Hosp Epidemiol. 2005;26:811-5.

98. Robicsek A, Beaumont JL, Paule SM, et al. Universal surveillance for methicillin-resistant Staphylococcus aureus in 3 affiliated hospitals. Ann Intern Med. 2008;148:409-18.

99. Vos MC, Behrendt MD, Melles DC, et al. 5 years of experience implementing a methicillin-resistant Staphylococcus aureus search and destroy policy at the largest university medical center in the Netherlands. Infect Control Hosp Epidemiol. 2009;30:977-84.

100. Jain R, Kralovic SM, Evans ME, et al. Veterans Affairs initiative to prevent methicillin-resistant Staphylococcus aureus infections. N Engl J Med. 2011;364:1419-30.

101. Datta R, Platt R, Yokoe DS, Huang SS. Environmental cleaning intervention and risk of acquiring multidrug-resistant organisms from prior room occupants. Arch Intern Med. 2011;171:491-4.

102. Murphy CR, Eells SJ, Quan V, et al. Methicillin-resistant Staphylococcus aureus burden in nursing homes associated with environmental contamination of common areas. J Am Geriatr Soc. 2012;60:1012-8.

103. Nicolle L, Bentley D, Garibaldi R, Neuhaus E, Smith P. Antimicrobial use in long-term-care facilities. Infect Control Hosp Epidemiol. 2000;21:537-45.

104. Smith D, Dushoff J, Perencevich E, Harris A, Levin S. Persistent colonization and the spread of antibiotic resistance in nosocomial pathogens: resistance is a regional problem. Proc Natl Acad Sci USA. 2004;101:3709-14.

105. Lee BY, Bartsch SM, Wong KF, et al. The importance of Nursing Homes in the spread of Methicillin-resistant Staphylococcus aureus (MRSA) among hospitals. Med Care. 2013;

106. Spindel SJ, Strausbaugh LJ, Jacobson C. Infections caused by Staphylococcus aureus in a Veterans' Affairs nursing home care unit: a 5-year experience. Infect Control Hosp Epidemiol. 1995; 16:217-23.

107. Lee YL, Cesario T, Gupta G, et al. Surveillance of colonization and infection with Staphylococcus aureus susceptible or resistant to methicillin in a community skilled-nursing facility. Am J Infect Control. 1997;25:312-21. 